\title{
Pre-service mathematics teachers' professional modeling competencies: a comparative study between Germany, Mainland China, and Hong Kong
}

\author{
Xinrong Yang ${ }^{1} \cdot$ Björn Schwarz ${ }^{2}$ (D) Issic K. C. Leung ${ }^{3}$
}

Accepted: 28 April 2021/Published online: 19 June 2021

(C) The Author(s) 2021

\begin{abstract}
Although mathematical modeling plays an important role in many curricula worldwide, significant discrepancies persist in the importance of mathematical modeling in ordinary mathematics classrooms and teacher education. This paper compares pre-service mathematics teachers' professional mathematical modeling competencies in three different regions - Germany, Mainland China, and Hong Kong - where educational and cultural traditions differ, including the role of mathematical modeling. In total, 232 pre-service mathematics teachers from the three regions completed a modeling task covering mathematics content knowledge (MCK) of modeling and mathematical pedagogical content knowledge (MPCK) of modeling. The results show that pre-service teachers from Germany demonstrated the strongest MCK and MPCK of mathematical modeling; by contrast, pre-service mathematics teachers from Mainland China and Hong Kong demonstrated relatively weaker MCK and MPCK of mathematical modeling. MCK and MPCK of mathematical modeling were also found to be unevenly developed at different competence levels for the three regions. These differences may be attributed to the history of mathematical modeling in mathematics curricula, teacher education, and teaching culture in these three regions.
\end{abstract}

Keywords Mathematics content knowledge $\cdot$ Mathematics pedagogical content knowledge Mathematical modeling · Teachers' professional competence

Björn Schwarz

bjoern.schwarz@uni-vechta.de

1 Southwest University, Chongqing, China

2 University of Vechta, Vechta, Germany

3 The Education University of Hong Kong, Hong Kong, China 


\section{Introduction}

Mathematical modeling has been a prominent research topic among the international mathematics education community for several decades and is now widely accepted as an essential component of mathematical literacy (e.g., Niss, 2015; OECD, 2003). Owing to its considerable international importance, in the latest reform of standards for school mathematics in many countries and regions, including Germany, Mainland China, and Hong Kong, mathematical modeling has been integrated into school curricula to promote connections between school mathematics and realworld situations (Kaiser, 2017; Ng, 2013). Scholars have noted, however, that day-to-day mathematics teaching includes few mathematical modeling examples (e.g., Blum, 2015; Tan \& Ang, 2016). Teachers' professional mathematical modeling competencies have been widely accepted as the key factor that determines the successful implementation of mathematical modeling in mathematics teaching (Barquero et al., 2018; Greefrath \& Vorhölter, 2016).

Mathematical modeling teaching poses substantial challenges to the common instructional practices to which teachers are accustomed (Doerr, 2007; Ng, 2013). In particular, various professional competencies that should "differ in some significant ways from traditional and reform-based methods for teaching mathematics" (Doerr, 2007, p. 70) are necessary to teach mathematical modeling. That is, new forms of mathematical and extra-mathematical knowledge and pedagogical content knowledge are necessary to teach mathematical modeling (Blum, 2015; Doerr, 2007; Kaiser \& Maaß, 2007). Indeed, mathematics content knowledge (MCK) and mathematical pedagogical content knowledge (MPCK) are the two main cognitive components of recently developed teacher professional competence frameworks, which also include affective components, such as beliefs (Weinert, 2001). Therefore, pre-service mathematics teachers must develop such professional competencies to minimize the potential occurrence of barriers to mathematical modeling teaching (Winter \& Venkat, 2013). However, in the field of mathematical modeling, few studies have investigated teachers' professional modeling competencies, in particular, the two most relevant competence components- $\mathrm{MCK}$ and MPCK - simultaneously.

Additionally, according to sociocultural theory, pre-service teachers' (PSTs') learning is mediated by specific social and cultural contexts; therefore, the shape and development of professional mathematical modeling competencies will differ from one context to another (Lerman, 2001). Indeed, clear differences in the underlying philosophy or deep-rooted values of mathematics education between Eastern and Western regions have been widely identified in the literature (Leung, 2001). In countries and regions in Eastern Asia, mathematics teaching emphasizes mathematics content and problem-solving skills, such as the emphasis on basic knowledge and basic skills in Mainland China (Ni et al., 2011). By contrast, the process of dealing with reality is one important part of mathematics teaching for Western countries and regions (Leung, 2001). For example, at the beginning of the twentieth century in Germany, Klein promoted a utilitarian mathematics education principle intended to enhance the capability to "deal with real life through a mathematical way of thinking" (Klein, 1907, p. 209).

Owing to such differences and despite the fact that mathematical modeling is now accepted as an integral part of school mathematics curricula in many countries and regions worldwide, the history and role of mathematical modeling at primary and secondary school levels varies internationally. For example, in Germany, mathematical modeling has played an important role for more than a century and has been intensified by German standards for mathematics education implemented since 2003, which describe mathematical modeling as a compulsory general competence at all school levels (Greefrath \& Vorhölter, 2016). By contrast, in Mainland China, 
mathematics curricula have a long tradition of emphasizing basic mathematics knowledge and basic mathematics skills without any strong relationship to real-world examples (Ni et al., 2011). However, mathematical modeling is now considered one of the six key mathematical competences in the senior secondary school mathematics curriculum (MOE, 2017). In Hong Kong, which has been influenced by both Western and Eastern cultures, the application of mathematics has long been emphasized, albeit strongly influenced by the British understanding of the application of mathematics, mainly in physics (Kong, 2000). However, mathematical modeling is mentioned in the latest school mathematics curriculum.

The content and organization of mathematics teacher training curricula also differ internationally (Tatto et al., 2009; Tatto et al., 2020). At many universities in Germany, pre-service mathematics teachers will have the opportunity to participate in mathematical modeling-related study courses. In Mainland China, an optional course on mathematical modeling focusing on mathematical modeling at the university level is offered only in parts of the pre-service mathematics teacher training universities. However, in Hong Kong, it is uncommon for preservice mathematics teachers to choose mathematical modeling courses.

Undoubtedly, the differences mentioned above will shape different social and cultural conditions and further provide different opportunities for PSTs to learn how to teach mathematical modeling. To the best of our knowledge, only a few recent studies have compared students' knowledge of mathematical modeling from different cultures (e.g., Chang et al., 2020; Hankeln, 2020). However, an investigation of the impact of pre-service teacher preparation on teachers' professional mathematical modeling competences is necessary to understand the variation in teaching quality and to facilitate the effective development of such professional competences. To achieve this aim, it is necessary to know more about the strengths and weaknesses of PSTs' professional competences with respect to specific themes and topics, and a cross-cultural comparative study seems appropriate for this. Adapting frameworks developed in previous comparative studies, namely Mathematics Teaching in the 21st Century (MT21) and Teacher Education and Development Study in Mathematics (TEDS-M), the present study aims to compare PSTs' professional mathematical modeling competences in Germany, Mainland China, and Hong Kong.

\section{Theoretical framework and literature review}

\subsection{Theoretical framework}

Interest in international comparative studies on mathematics teachers' professional competencies has recently increased (e.g., Bryan et al., 2007; Kleickmann et al., 2015). One influential international study of pre-service mathematics teacher education was TEDS-M (for lower secondary level mathematics teachers Blömeke et al., 2010b), in which a conceptual model of mathematics teachers' professional competencies was developed and adopted as a theoretical framework.

Departing from the important work by Weinert (2001), TEDS-M conceptualizes teachers' professional competences as comprising cognitive facets (e.g., teachers' professional knowledge) and affective-motivational facets (e.g., beliefs). For teachers' professional knowledge, referring to the seminal work by Shulman (1986), among others, the following three facets of the professional knowledge of teachers were distinguished: MCK, MPCK, and general pedagogical knowledge (Blömeke et al., 2010b). The present study concerns the mathematical 
aspects of cognitive facets of professional competence-MCK and MPCK - and refers these areas of knowledge to mathematical modeling.

Regarding MCK, it is widely accepted that teachers require a profound understanding of mathematical content to successfully accomplish their professional activities, which also applies to mathematical modeling teaching (Blömeke \& Delaney, 2012). However, many studies have described mathematical modeling as a cyclic and iterative process that includes different modeling sub-processes and requires the ability to translate between reality and mathematics in both directions (e.g., Blum \& Leiß, 2007; Galbraith \& Stillman, 2006). To successfully teach mathematical modeling, pure MCK alone is insufficient (Hankeln, 2020). Teachers must also possess a solid foundational knowledge of the world of mathematics for modeling activities (Blum \& Niss, 1991). More importantly, teachers must comprehensively understand the relationship between the extra-mathematical world and the world of mathematics to perform various sub-processes, such as simplifying, mathematizing, interpreting, and validating. Therefore, modeling MCK in the present study refers to sub-competences for carrying out modeling processes and meta-cognitive modeling competencies (e.g., reflecting critically on executed modeling) (Kaiser, 2017).

Pedagogical content knowledge (PCK) mainly denotes subject-specific knowledge that is focused on making subject matter accessible to students (Shulman, 1986). Shulman (1986) identified two components that are central to PCK: knowledge of instructional strategies and representations and knowledge of students' (mis)conceptions. Specific frameworks for mathematical modeling PCK have been developed. For example, Borromeo Ferri and Blum (2010) distinguished four dimensions: (1) a theoretical dimension, including modeling cycles or aims and perspectives of modeling as background knowledge; (2) a task dimension, including multiple solutions or cognitive analyses of modeling; (3) an instructional dimension-for example, teachers need to know how to make appropriate interventions, give students proper support, and provide timely feedback; and (4) a diagnostic dimension, such as the ability to recognize students' difficulties and mistakes.

Cetinkaya et al. (2016) further detail the MPCK of mathematical modeling from the perspective of the "pedagogy of mathematical modeling." Referring to previous discussions relating to pedagogical knowledge of mathematical modeling, they distinguish several aspects that are required for mathematical modeling teaching in the classroom: (1) knowing a given modeling task's cognitive demands; (2) knowing how to organize classroom discourse and how to manage the classroom during modeling activities; (3) providing adaptive, independencepreserving, and strategic interventions; (4) interpretive listening, recognizing, and responding to students' thinking; (5) recognizing productive versus less productive paths in the modeling process; and (6) recognizing unexpected solution approaches and developing coping strategies.

To summarize, these earlier studies' rich discussions of MPCK of mathematical modeling mainly relate to teaching-related aspects, such as task-related knowledge, teaching methods, and assessment, and learning-related aspects, such as students' possible solutions, difficulties, and mistakes (Maaß \& Gurlitt, 2011). Therefore, like the approaches discussed in these previous studies and following respective conceptualizations of MPCK in TEDS-M (Döhrmann et al., 2010) and MT21 (Blömeke et al., 2008), in the present study, MPCK of mathematical modeling was generally categorized into two aspects: (1) the learning process perspective, which mainly includes teachers' knowledge with respect to evaluating students' answers and providing feedback, and (2) the teaching perspective, which mainly concerns teachers' knowledge with respect to explaining the adequacy of the modeling task and choosing the appropriate teaching approach (Fig. 1). 


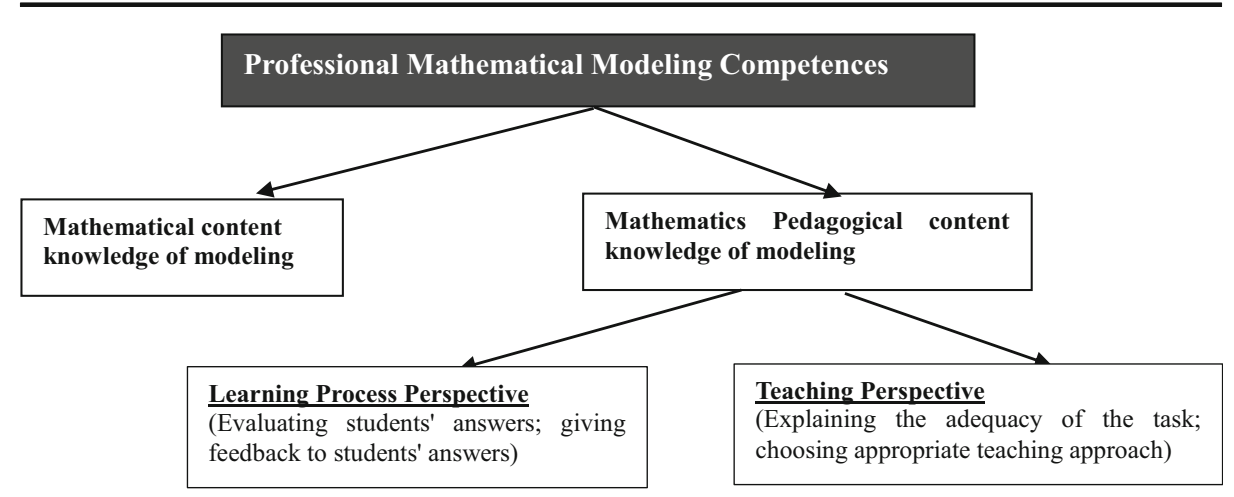

Fig. 1 Framework of professional mathematical modeling competences

Concerning the relationship between MCK and MPCK, the present study understands MCK and MPCK as separate domains with MCK also contributing to MPCK. The latter follows from the assumption that thinking about the teaching and learning of mathematics under both aspects - the learning process perspective and the teaching perspective - requires the consideration of subject-related aspects. However, MPCK is not a sub-dimension of MCK; rather, it requires the integration and even the adjustment of subject-related knowledge into multifaceted pedagogical considerations. Thus, concerning the relationship between MPCK and MCK, the present study begins from the assumption that MCK and MPCK can be separated both theoretically and empirically but that they correlate, as has been shown for MCK and MPCK in general aside from the focus on modeling (Blömeke et al., 2010a; Brunner et al., 2006; Charalambous et al., 2020). Against the background of the varying strength of the correlations between MCK and MPCK in an international comparison (Blömeke et al., 2010a), the study also expects possible cross-national differences concerning the relation between MCK and MPCK. Furthermore, it is assumed that the relationship between MCK and MPCK is not necessarily homogenous within a single sample but might differ with respect to the theoretically based differentiations of MPCK (that is, with respect to the teaching perspective and the learning perspective and sub-differentiations).

\subsection{Related previous studies}

A small number of studies have investigated teachers' knowledge in the field of mathematical modeling research. For teachers' MCK of mathematical modeling, the findings reported in previous studies can be roughly classified into two aspects. The first relates to teachers' understanding of the essential characteristics or meaning of mathematical modeling (e.g., Anhalt \& Cortez, 2016; Cetinkaya et al., 2016). Many pre-service and in-service mathematics teachers were found to have misunderstood the nature of mathematical modeling before participating in specifically designed teacher development programs. The other aspect is that many teachers experienced difficulties concerning specific sub-processes of the mathematical modeling cycle. For example, Tan and Ang (2013) found that PSTs could interpret real-world situations and identify important quantities, but some teachers struggled to recognize the need to uncover relationships between variables and failed to interpret mathematical solutions in real situations or to validate their mathematical models. Anhalt et al. (2018) also found that PSTs could make appropriate assumptions and simplifications and mathematize relevant quantities and their relations, but some participants showed low proficiency in interpreting 
mathematical results in real-life contexts, and only half were able to suggest alternative approaches.

Regarding teachers' MPCK of mathematical modeling, researchers have investigated teachers' knowledge of modeling tasks and found that many teachers' knowledge is limited. For example, Kuntze (2011) found that the majority of 230 PSTs rated tasks with higher modeling requirements as having lower learning potential than tasks with lower modeling requirements. Such findings suggest that most PSTs were not fully aware of the possibilities and potentials of modeling tasks. Similarly, $\mathrm{Ng}$ (2013) found that some teachers were unable to appreciate the potential of modeling activities because they lacked prior modeling experience. Other researchers investigated PSTs' ability to pose mathematical modeling problems to their students. For example, Paolucci and Wessels (2017) found that the PSTs were inclined to create problems for more advanced students, and nearly $60 \%$ of the participants missed or incorrectly identified at least one content area related to their modeling problems. They further identified that most PSTs struggled to create tasks requiring learners to construct mathematical representations of the contexts.

Other studies reported that mathematics teachers struggle to interpret students' thinking as reflected in the students' mathematical modeling works. For example, Didis et al. (2016) found that PSTs could not thoroughly interpret students' ways of thinking in mathematical modeling tasks and mostly focused on the correctness of the students' answers while oversimplifying students' mathematical ideas. Moreover, it was reported that teachers struggle to facilitate students' progression from one stage to the next during the modeling process. For example, $\mathrm{Ng}$ et al. (2015) found that teachers in their study faced challenges in (1) striking a balance between questioning and listening and (2) fostering metacognition in students.

Studies have also investigated the relationship between teachers' MCK and MPCK of mathematical modeling, despite the fact that it was not clearly noted as a research goal. For example, Didis et al. (2016) found that some PSTs' insufficient MCK of mathematical modeling presented them with difficulties in recognizing and interpreting students' mathematical thinking. However, other studies reported that PSTs' profound knowledge of the modeling process may not necessarily imply that they are profoundly knowledgeable about how to teach modeling. For example, Kaiser et al. (2010) reported that although one teacher possessed a sound content knowledge of modeling, he could not relate this knowledge to the didactic aims associated with mathematical modeling. By contrast, another teacher, who lacked a sound MCK of modeling, had clear and concrete ideas of the aims of modeling teaching. Such findings suggest that teachers' MCK and MPCK of modeling are not necessarily evenly developed. Indeed, Doerr and English (2006) found that after the same intervention, one teacher mainly developed knowledge of mathematics content of the problem, while the other teacher mainly developed new MPCK.

As described above, research in mathematical modeling in the field of mathematics teacher education has expanded in recent years; however, the main goal of most studies' was to explore the effectiveness of a specific design-based training program. Overall, according to Tan and Ang (2016, p. 403), "little is known about professional development for teachers' competencies in teaching mathematical modelling." To effectively facilitate the growth of teachers' professional competencies, a clear understanding of the main influencing factors is necessary. Cross-cultural comparative studies can therefore help to identify the main strengths and weaknesses of teachers' professional mathematical modeling competences in different social and cultural contexts. Such studies may also further facilitate exploration of how specific social and cultural contexts influence the shape and development of PSTs' professional 
competences of mathematical modeling. In view of these, the present study is guided by the following research questions:

1) What competency levels with respect to MCK and MPCK are evident in samples of PSTs in Germany, Hong Kong, and Mainland China?

2) Do the samples differ in their level and structure of competencies?

3) Can any relationships between MCK and MPCK be identified in the three regions?

\section{Design of the study and research methods}

To address the research questions, the PSTs' cognitive facets of competence were evaluated using an open-item questionnaire covering PSTs' modeling-related MCK and MPCK. The instruments were developed by Schwarz (2013) and adapted and translated for use in a cross-cultural study. The questionnaire, the sample, and the data evaluation methods are presented below.

\subsection{Participants}

The overall sample comprised 232 PSTs from three regions: Mainland China, Hong Kong, and Germany. The German sample consists of 79 PSTs from a university in Germany and covers both beginners and advanced students. In Germany, a consecutive preparation model consisting of a first phase in university and a second phase of in-service-training is implemented. All participants had studied mathematics for teaching at the lower secondary level combined either with primary $(n=47)$ or upper secondary level $(n=32)$. Regarding the twophase model of teacher education in Germany, all German PSTs were in their first phase of teacher education. In this phase, the focus is on subject matter-related education and pedagogical studies, the latter including didactical courses.

Eighty-four PSTs were chosen from two teacher education institutions, normal universities, in Mainland China. Currently, teacher education universities generally provide 4-year bachelor's programs for PSTs. In Mainland China, a preparation model that concurrently delivers general and professional education is implemented with greater emphasis on extensive training in mathematics than on mathematics pedagogy training (Tatto et al., 2009). The PSTs were all in their fourth year of study and therefore close to completing their university degrees. Thirtyfive had already completed their teaching practicum in senior secondary schools, and the other 49 had completed their 18-week teaching practicum in junior secondary schools. All were qualified to teach secondary school mathematics after graduation.

Sixty-nine PSTs were chosen from a teacher education institution in Hong Kong, where the two modes - consecutive and concurrent preparation - are both used with major emphasis on concurrent training in mathematics (Leung, 2017). All participants were chosen from a concurrent preparation program and were attending a 4-year bachelor's program for PST training. Similarly, the 69 PSTs were also in their fourth year, and all had acquired teaching experience in both primary and secondary schools in Hong Kong for one semester.

All PSTs participated voluntarily and had time to complete the questionnaire during the seminar. As all participants in the courses were studying to become mathematics teachers and therefore fulfilled the criteria for the sample (i.e., PST for mathematics), no further selection process was conducted; instead, all questionnaires were evaluated. 


\subsection{Research instrument}

The evaluation of the cross-cultural study was based on one task with five items with each item aligning with one area of professional competencies, such as MCK and MPCK of mathematical modeling ${ }^{1}$ (from Schwarz, 2013, translated); the original instrument contained more tasks, not all of which were limited to modeling.

The task's starting point was a modeling exercise for lower secondary students (slightly modified from Maaß, 2004). The PSTs were then asked to first solve the modeling problem independently before four different interviews with students (from the unpublished supplement to Maßß, 2004) were presented. Afterward, the PSTs were asked to analyze the students' thinking from a content-related perspective and to formulate responses to the four students' answers, providing feedback to each. In the next items, the PSTs evaluated the appropriateness of the task for junior secondary school students and described which teaching method they would use when teaching such an exercise in their mathematics lessons.

\subsection{Data evaluation methods}

All data were coded according to the qualitative content analysis approach (Kuckartz, 2016; Mayring, 2014) using deductively defined codes. This means that both the overall categories according to which the data were evaluated, and the possible values for each category and the respective coding rules were theoretically defined prior to data evaluation. Together with answers from the data, which either illustrate typical answers or answers that are "on the border" of a value - so-called "anchor-answers" - the categories, values, and coding rules form the coding manual. All items were coded using an ordinal scale. As the items focus on cognitive facets of competence - either MCK or MPCK - the answers' degree of adequacy is covered by the code. A more detailed description of the different data evaluation steps and a sample of the coding manual are provided in the appendix.

Despite previous attempts to formulate precise coding rules, the method still entails an act of data interpretation. Therefore, all data were coded by the researchers or intensively trained raters, who had been introduced to both the underlying theoretical background and the evaluation method. In particular, the raters' introduction to the theoretical background should help to maximize the adequate interpretation of the various answers with their different emphases and solution attempts. The coding manual was translated into English to facilitate exchange within the research group. To prevent any misunderstandings arising from translations, data from the various regions were kept in the original languages and were evaluated by raters who were proficient in the respective languages. To ensure the reliability of the data evaluation, all data were coded by two raters in different phases. More precisely, two coders independently coded approximately $25 \%$ of the German data and noted possible ambiguities in the upfront-formulated coding manuals. The coding manuals were revised based on these ambiguities and cases in which the raters selected different codes.

Using these manuals, the project followed Mayring's (2014) suggestions concerning intercoder agreement. Therefore, all data were coded by two raters independently ("the best way for most Qualitative Content Analysis projects" (Mayring, 2014, p. 114)). Afterward, both

\footnotetext{
${ }^{1}$ A detailed description of the questions can be found in the appendix.
} 
Table 1 Cohen's kappa for the coded items in the three regions

\begin{tabular}{llll}
\hline & \multicolumn{2}{l}{ Cohens Kappa } \\
\cline { 2 - 4 } Item & Germany & Mainland China Hong Kong \\
\hline MCK & 0.82 & 0.91 & 0.84 \\
MPCK - learning process perspective (evaluating students' answers) & 0.66 & 0.82 & 0.87 \\
$\begin{array}{l}\text { MPCK - learning process perspective (providing feedback } \\
\text { to students' answers) }\end{array}$ & 0.81 & 0.86 & 0.88 \\
$\begin{array}{l}\text { MPCK - teaching perspective (explaining the appropriateness } \\
\text { of the task) }\end{array}$ & 0.88 & 0.92 & 0.91 \\
$\begin{array}{l}\text { MPCK - teaching perspective (proposing an appropriate } \\
\text { teaching approach) }\end{array}$ & 0.86 & 0.89 & 0.87 \\
\hline
\end{tabular}

raters discussed their codings, focusing particularly on the cases that they had coded differently. If the different codes arose as a result of ambiguities remaining in the coding manual, that particular part was revised, and the data were re-coded. These re-worked manuals later formed the basis for the coding in the other regions. If different interpretations of the data were the reason for different codes in all regions, the raters discussed their different understandings, with the result that they either agreed on one code or retained two different codes owing to persistently different understandings of the respective aspects of the data. This is in line with Mayring's methodological considerations that "interpretative elements [...] always bear a subjective element" (Mayring, 2014, p. 114). The Cohen's kappa values for the items are presented in Table 1 and are satisfactory for all three regions.

In the next step, which involved all coders, one coder's coding was selected to avoid the reduction of the material by excluding all cases with different codings. Corresponding to the research question focusing on the comparison of the different PST groups, the coded data were evaluated using basic quantitative methods, such as frequency analyses. Chi-square tests and post hoc analyses were further performed to determine whether each component of the assessed professional competencies across the three regions differed significantly. In view of the relatively small sample size, no generalization was intended; rather, the study is considered to provide first insights into answering patterns in the three regions under comparison.

\section{Findings}

The two sections that follow address the first and second research question-that is, the PSTs' competency levels with respect to MCK (Sect. 4.1) and MPCK (Sect. 4.2) - and analyze the differences between the three regions. Subsequently, in Sect. 4.3, the third research question concerning the relations between MCK and MPCK in the three regions is addressed.

\subsection{Levels and differences in mathematical content knowledge of modeling}

First, PSTs' MCK of modeling was investigated by asking the participants to solve the modeling task independently. PSTs' answers were categorized into five levels depending on how many central aspects of a modeling cycle (development of a real model and a mathematical model, interpretation of the results) the PSTs adequately work on in their solution (one aspect average level, two aspects high level, three aspects very high level) or whether they only 
Table 2 Distribution of the levels of MCK

\begin{tabular}{llll}
\hline & Germany $(N=79)$ & Hong Kong $(N=69)$ & Mainland China $(N=84)$ \\
\hline+2 (very high level) & $7(8.9 \%)$ & $6(8.7 \%)$ & $8(9.5)$ \\
+1 (high level) & $26(32.9 \%)$ & $8(11.6 \%)$ & $19(22.6 \%)$ \\
0 (average level) & $27(34.2 \%)$ & $25(36.2 \%)$ & $33(39.3 \%)$ \\
-1 (low level) & $8(10.1 \%)$ & $24(34.8 \%)$ & $22(26.2 \%)$ \\
-2 (very low level) & $8(10.1 \%)$ & $5(7.2 \%)$ & $2(2.4 \%)$ \\
\hline
\end{tabular}

adopt ideas given in the task (low level) or whether they formulate a model which is not adequate for the task (very low level). The results are summarized in Table $2^{2}$.

As Table 2 shows, the first main result by comparing the achievements of PSTs from the three regions is that very few participants (less than 10\%) possessed very high mathematical modeling competency levels. That is, in each of the three regions, less than $10 \%$ of the participants could solve the task correctly. Interestingly, few PSTs - particularly in Mainland China - achieved very low professional mathematical modeling competency levels.

The chi-square test result $\left(\chi^{2}(8, N=228)=22.63, p<0.01\right)$ shows that the distributions of each level of MCK of mathematical modeling across the three regions differed significantly. Bonferroni-adjusted post hoc tests show that the proportion of PST at low levels in Mainland China $(26.2 \%)$ and in Hong Kong $(34.8 \%)$ is significantly greater than the proportion in Germany $(10.1 \%)$, with $p=0.034$ and $p=0.001$, respectively. By contrast, post hoc test results show that for the high level, the proportion of PST in Hong Kong (11.6\%) is significantly lower than the proportion in Germany (32.9\%) with $p=0.005$. The results suggest that PSTs from Germany were identified as having a stronger MCK foundation in modeling compared with those from Hong Kong and Mainland China.

\subsection{Levels and differences in mathematics pedagogical content knowledge of modeling}

For the learning perspective of PSTs' MPCK of mathematical modeling, the evaluation of students' answers and the provision of feedback to students' answers were specifically investigated. PSTs' MPCK of modeling from the learning perspective was also categorized across five levels - very high, high, average, low, and very low. For the first aspect, participants were required to evaluate the appropriateness of four students' approaches to the modeling example. PSTs' answers were categorized into five levels depending on how many students' approaches they adequately could assign a strength or weakness to. Table 3 summarizes the results of the evaluation of the PST's answers.

A central difference from the preceding result about MCK is that, with respect to MPCK, both the highest and lowest levels were reached more often within all three groups (with the exception of the lowest level in the German sample, which was reached at a similar frequency to that of MCK). The chi-square test result $\left(\left(\chi^{2}(8, N=219)=34.43, p<0.001\right)\right.$ shows that the distribution across the three regions differs significantly. Bonferroni-adjusted post hoc tests show that compared with PSTs from Germany, significantly more teachers from Hong Kong were found to reach a very low level $(p<0.001)$, and significantly fewer teachers were found to

\footnotetext{
${ }^{2}$ As some PSTs left out some questionnaire items or formulated no meaningful answers, the total number in the analyses is in some cases less than the sample-size.
} 
Table 3 Distribution of the levels of MPCK with regard to evaluating students' answers

\begin{tabular}{llll}
\hline & Germany $(N=79)$ & Hong Kong $(N=69)$ & Mainland China $(N=84)$ \\
\hline+2 (very high level) & $20(25.3 \%)$ & $10(14.5 \%)$ & $10(11.9 \%)$ \\
+1 (high level) & $27(34.2 \%)$ & $6(8.7 \%)$ & $18(21.4 \%)$ \\
0 (average level) & $12(15.2 \%)$ & $5(7.2 \%)$ & $13(15.5 \%)$ \\
-1 (low level) & $8(10.1 \%)$ & $13(18.8 \%)$ & $23(27.4 \%)$ \\
-2 (very low level) & $10(12.7 \%)$ & $26(37.7 \%)$ & $18(21.4 \%)$ \\
\hline
\end{tabular}

reach a high level $(p=0.002)$. Post hoc test results also show that the proportion of PSTs in Mainland China at a very low level differs from that of Hong Kong's PSTs $(p=0.019)$, but the proportion of PSTs in Mainland China at a low level is different to that of German PSTs $(p=0.015)$. Results as such again suggest that in line with the preceding result regarding MCK, relatively more German PSTs reached at least the high level, and more PSTs from Mainland China and Hong Kong reached at least the low level.

To investigate PSTs' competencies in providing feedback to students' answers, each participant was required to respond to the four students' answers. PSTs' answers were again categorized into five levels depending on how many students' approaches the PSTs adequately could formulate an individual learning aid for in a sense of a meaningful perspective for the student to work on. Table 4 summarizes the results related to this aspect, which differ from the preceding results. The chi-square test result $\left(\left(\chi^{2}(8, N=223)=9.94, p=0.269\right)\right.$ shows that the distribution does not differ significantly across the three regions. However, in this item, more PSTs from Hong Kong and Mainland China reached the highest level compared to the German participants. Furthermore, all participants appeared to find the task difficult, as more than half of the PSTs from all three regions only achieved low and very low levels.

For the teaching perspective of MPCK of mathematical modeling, the teachers' competencies in explaining the task's appropriateness and suggesting appropriate teaching approaches were specifically investigated.

Table 5 summarizes the results related to PSTs' competencies in explaining whether the task is appropriate for students at the secondary school level and why. PSTs' answers here were categorized into three levels depending on whether the PSTs with or without sound argumentation correctly accept the modelling task as a possible part of mathematics teaching or incorrectly do not accept it. The chi-square test result $\left(\left(\chi^{2}(4, N=221)=26.19, p<0.001\right)\right.$ suggests a significant difference in distribution across the three regions. Bonferroni-adjusted post hoc tests further show that compared with the proportion of Hong Kong PSTs $(11.6 \%)$ at high level, the proportion of PSTs in Germany $(41.8 \%, p<0.001)$ and Mainland China $(41.7 \%$, $p<0.001)$ was found to be significantly greater. By contrast, again, the proportion of Hong Kong PSTs (26.1\%) at the low level differs significantly from that of German PSTs (6.3\%)

Table 4 Distribution of the levels of MPCK with regard to providing feedback to students' answers

\begin{tabular}{llll}
\hline & Germany $(N=79)$ & Hong Kong $(N=69)$ & Mainland China $(N=84)$ \\
\hline+2 (very high level) & $4(5.1 \%)$ & $11(15.9 \%)$ & $13(15.5 \%)$ \\
+1 (high level) & $14(17.7 \%)$ & $7(10.1 \%)$ & $8(9.5 \%)$ \\
0 (average level) & $12(15.2 \%)$ & $8(11.6 \%)$ & $10(11.9 \%)$ \\
-1 (low level) & $11(13.9 \%)$ & $5(7.2 \%)$ & $10(11.9 \%)$ \\
-2 (very low level) & $34(43.0 \%)$ & $33(47.8 \%)$ & $43(51.2 \%)$ \\
\hline
\end{tabular}


Table 5 Distribution of the levels of MPCK with regard to explaining task appropriateness

\begin{tabular}{llll}
\hline & Germany $(N=79)$ & Hong Kong $(N=69)$ & Mainland China $(N=84)$ \\
\hline+1 (high level) & $33(41.8 \%)$ & $8(11.6 \%)$ & $35(41.7 \%)$ \\
0 (average level) & $36(45.6 \%)$ & $39(56.5 \%)$ & $30(35.7 \%)$ \\
-1 (low level) & $5(6.3 \%)$ & $18(26.1 \%)$ & $17(20.2 \%)$ \\
\hline
\end{tabular}

Table 6 Distribution of the MPCK levels with respect to proposing an appropriate teaching approach

\begin{tabular}{llll}
\hline & Germany $(N=79)$ & Hong Kong $(N=69)$ & Mainland China $(N=84)$ \\
\hline+1 (high level) & $33(41.8 \%)$ & $15(21.7 \%)$ & $22(26.2 \%)$ \\
0 (average level) & $38(48.1 \%)$ & $23(33.3 \%)$ & $37(44.0 \%)$ \\
-1 (low level) & $5(6.3 \%)$ & $24(34.8 \%)$ & $24(28.6 \%)$ \\
\hline
\end{tabular}

with $p=0.003$. Post hoc tests show that the proportion of Hong Kong's PSTs $(56.5 \%)$ at the average level differs significantly from that of Mainland China's PSTs (35.7\%) with $p=0.029$.

Regarding the second aspect of the teaching perspective, the participants were required to suggest a teaching approach to the task appropriate to Grade 8 students. PSTs' answers here were again categorized into three levels depending on whether the PSTs with or without sound reasoning could formulate an adequate teaching approach or whether they could not do so. Table 6 summarizes the results for this aspect. Similarly, the chi-square test result $\left(\left(\chi^{2}(4, N=\right.\right.$ $221)=22.44, p<0.001)$ shows significant differences in the distribution across the three regions. Bonferroni-adjusted post hoc tests show that for the low level, the proportions of PSTs in Mainland China (28.6\%) and Hong Kong (34.8\%) differ significantly from the proportion (6.3\%) in Germany with $p=0.001$ and $p<0.001$, respectively.

\subsection{Relationship between MCK and MPCK of mathematical modeling}

To explore the relationship between PSTs' MCK and MPCK of mathematical modeling, the distribution of participants' performance of the four aspects of MPCK of mathematical modeling at different levels of MCK of mathematical modeling was analyzed across the three regions. Table 7 summarizes the results. Several patterns may be identified.

Firstly, PSTs with strong MCK foundations with respect to mathematical modeling do not necessarily show high levels of MPCK of mathematical modeling accordingly. As Table 7 indicates, in all three regions, only around a half (for Germany) or even less than half (for Hong Kong and Mainland China) of PSTs who reached high or very high levels of MCK of mathematical modeling were further found to demonstrate corresponding levels of MPCK of mathematical modeling. By contrast, almost more than half of the PSTs experienced difficulties in the four MPCK-related aspects.

Secondly, for those PSTs with weak MCK in mathematical modeling, it appears probable that their MPCK of mathematical modeling will also be poor. As Table 7 illustrates, more than half of those PSTs who only reached average, low, and very low levels of MCK of mathematical modeling were found to show average or low levels of MPCK with one exception on the aspect of evaluating students' answers in Germany.

Thirdly, for those participating PSTs with poor MCK of mathematical modeling, a small number still showed a high level of MPCK. As shown in Table 7, some PSTs (especially 
Table 7 Distribution of each aspect of MPCK of different levels of MCK of mathematical modeling (by percentage)

\begin{tabular}{|c|c|c|c|c|c|c|c|c|c|c|c|c|c|}
\hline & & \multicolumn{3}{|c|}{$\begin{array}{l}\text { Evaluating } \\
\text { answers }\end{array}$} & \multicolumn{3}{|c|}{$\begin{array}{l}\text { Providing } \\
\text { feedback }\end{array}$} & \multicolumn{3}{|c|}{$\begin{array}{l}\text { Explaining } \\
\text { appropriateness }\end{array}$} & \multicolumn{3}{|c|}{$\begin{array}{l}\text { Teaching } \\
\text { approach }\end{array}$} \\
\hline & & $2 / 1$ & 0 & $-1 /-2$ & $2 / 1$ & 0 & $-1 /-2$ & +1 & 0 & -1 & +1 & 0 & -1 \\
\hline \multirow[t]{3}{*}{ Germany } & $\begin{array}{l}\text { MCK (very high/high } \\
\quad \text { level, } n=33 \text { ) }\end{array}$ & 57. & 627.2 & 15.2 & 33.3 & 12.1 & 51.5 & 48.5 & 51.5 & 0 & 54.5 & 39.4 & 6.1 \\
\hline & $\begin{array}{l}\text { MCK } \\
\text { (average level, } n=27 \text { ) }\end{array}$ & 66. & 73.7 & 29.6 & 18.5 & 18.5 & 59.3 & 33.3 & 44.4 & 7.4 & 33.3 & 48.1 & 11.1 \\
\hline & $\begin{array}{l}\text { MCK (low/very low } \\
\text { level, } n=16)\end{array}$ & 56. & 312.5 & 25.0 & 12.5 & 12.5 & 68.8 & 43.8 & 37.5 & 18.8 & 31.3 & 68.7 & 0 \\
\hline \multirow[t]{3}{*}{$\begin{array}{l}\text { Hong } \\
\text { Kong }\end{array}$} & $\begin{array}{c}\text { MCK (very high/very } \\
\text { high level, } n=14 \text { ) }\end{array}$ & 35. & 714.3 & 42.9 & 21.4 & 14.3 & 64.3 & 14.3 & 71.4 & 14.3 & 28.6 & 28.6 & 28.6 \\
\hline & $\begin{array}{l}\text { MCK } \\
\text { (average level, } n=25 \text { ) }\end{array}$ & 20. & 04.0 & 56.0 & 32.0 & 8.0 & 48.0 & 20.0 & 48.0 & 20.0 & 24.0 & 32.0 & 32.0 \\
\hline & $\begin{array}{l}\text { MCK (low/very low } \\
\text { level, } n=29)\end{array}$ & 6.9 & 17.2 & 65.5 & 13.8 & 24.1 & 55.2 & 3.4 & 55.2 & 37.9 & 17.2 & 34.5 & 41.4 \\
\hline \multirow[t]{3}{*}{$\begin{array}{l}\text { Mainland } \\
\text { China }\end{array}$} & $\begin{array}{c}\text { MCK (veryhigh/very } \\
\text { high level, } n=27 \text { ) }\end{array}$ & 25. & 922.2 & 48.1 & 14.8 & 14.8 & 70.4 & 48.1 & 29.6 & 18.5 & 55.6 & 33.3 & 11.1 \\
\hline & $\begin{array}{l}\text { MCK } \\
\text { (average level, } n=33 \text { ) }\end{array}$ & 30. & 312.1 & 57.6 & 21.2 & 12.1 & 66.7 & 39.4 & 39.4 & 21.2 & 18.2 & 60.6 & 21.2 \\
\hline & $\begin{array}{l}\text { MCK (low/very low } \\
\text { level, } n=24 \text { ) }\end{array}$ & 45. & 812.5 & 37.5 & 41.7 & 8.3 & 50.0 & 37.5 & 45.8 & 16.7 & 8.3 & 33.3 & 58.3 \\
\hline
\end{tabular}

participants from Germany and Mainland China) with poorer performance in MCK were found to reach at least an average level with regard to explaining the appropriateness of a modeling task for secondary mathematics teaching.

Another tendency could be identified from the distribution in Table 7: the relationship between MCK of mathematical modeling and the distinguished aspects of MPCK of mathematical modeling varies. More PSTs (especially for those in Germany and Mainland China) with high MCK levels were found to attain high levels in explaining the task's appropriateness and in suggesting a teaching approach. By contrast, more PSTs with high MCK levels were found to experience difficulties in providing feedback on students' answers. In addition, relatively more PSTs in Germany and Mainland China with low or very low level of MCK were found to attain high levels in the aspects of evaluating answers and explaining the appropriateness of tasks.

\section{Discussion}

\subsection{Discussion of MCK on mathematical modeling}

Regarding MCK of mathematical modeling, a general pattern identified in the study is that few PSTs in the three regions were found to possess very high mathematical modeling competency levels. Earlier studies have reported similar findings. For example, as noted above, PSTs were typically found to experience difficulties at some stages of the mathematical modeling cycle, particularly at the stages of interpreting and validating (Anhalt et al., 2018; Tan \& Ang, 2013).

The second pattern observed in PSTs' MCK of mathematical modeling is that those PSTs from Germany demonstrated the strongest professional competencies in this aspect, with more 
than $40 \%$ of them achieving the two highest levels and only around $20 \%$ achieving the two lowest levels. By contrast, the post hoc analysis results in particular showed that significantly more PSTs from the two other regions - particularly those from Hong Kong-demonstrated significantly weaker professional competencies. Around $30 \%$ to $40 \%$ of the participants in Mainland China and Hong Kong could not provide satisfactory answers to at least one of the three assessed aspects.

The differences between the three regions may be explained in the first instance by the differences in mathematics teaching traditions between the three regions. As mentioned above, in Hong Kong and particularly in Mainland China, the focus and goal of mathematics education is to acquire mathematical knowledge and routine mathematical problem-solving skills; however, in Western countries such as Germany, it is a long-standing tradition to teach students how to apply mathematics in the real world (Leung, 2001). In contrast to Germany, mathematics teaching in Mainland China and Hong Kong emphasizes accurate and abstract mathematics; therefore, students in these two regions will have fewer opportunities to apply mathematics in real-life situations. Therefore, it is understandable that a considerable number of PSTs from Hong Kong and Mainland China exhibited weak professional competencies in the MCK aspect.

Additionally, the historical development of the mathematics curricula - particularly differences in the role and relevance of mathematical modeling in primary and secondary school mathematics curricula in the three regions - may further explain these differences. As described earlier, mathematical modeling has been discussed for several decades in Germany, in contrast to Mainland China and Hong Kong, where mathematical modeling has only recently been included in the reformed mathematics curriculum. It is widely accepted that teachers will require time to accept such reformed ideas to implement modeling-related tasks in ordinary teaching (Lloyd, 1999). Therefore, PSTs in Germany may have commonly experienced mathematical modeling when they themselves attended school. Hong Kong's PSTs may have experienced mathematics applications, as such examples have been emphasized in school mathematics curricula there for many years; however, essential differences are evident between the traditional British understanding of mathematics application mainly in mechanics and mathematical modeling (for details, see Kaiser, 1995). It was therefore expected that most PSTs would be unable to solve a secondary school-level mathematical modeling problem. Similarly, in Mainland China, many PSTs may also not have had the opportunity to experience mathematical modeling.

However, the emphasis on acquiring sound mathematical knowledge in Hong Kong and Mainland China may help to explain that some participants from these regions demonstrated high or very high MCK of mathematical modeling levels. A recent cross-cultural study between Germany and Taiwan on students' mathematical modeling knowledge found that when students have high conceptual knowledge of mathematics, they might have similar high modeling competence (Chang et al., 2020).

In addition, the differences in pre-service training courses may further contribute to explaining the differences between the three groups. At many German universities, PSTs will participate in mathematical modeling-related study courses. Currently, in Mainland China, an optional course on mathematical modeling is available only in some teacher training universities. However, in Hong Kong, it is uncommon for PSTs to take mathematical modeling courses. Therefore, it is not unexpected that PSTs from Hong Kong will demonstrate the weakest MCK of mathematical modeling among the three groups. In addition, it was therefore expected that no significant differences between Mainland China and Germany would exist, as the post hoc analysis revealed. Rather, around 30\% of PSTs from Mainland China attained high or very high MCK of mathematical modeling levels. 


\subsection{Discussion of MPCK of mathematical modeling}

Regarding PSTs' MPCK of mathematical modeling, first - for the two aspects related to the learning perspective - it appears that providing feedback on students' answers is relatively more difficult or demanding than evaluating students' answers, particularly for PSTs from Germany and Mainland China. This may be due to the lack of practical experience in successfully interpreting students' mathematical modeling thinking processes. Based on the literature, it is known that PSTs were unable to interpret students' mathematical thinking underlying a specific mathematical task or were inclined to oversimplify students' mathematical ideas (Didis et al., 2016). Some PSTs in the present study also did not know how to highlight errors in the four students' answers and, consequently, did not know how to provide viable feedback. As described earlier, some PSTs in Germany and Mainland China may already have modeling experience from when they were in school (for German PSTs) and during PST training (for both). Therefore, they may know more about how specific modeling tasks should be analyzed compared to providing feedback. This explanation is supported by existing studies, which report PSTs' difficulties in suggesting alternative approaches (Anhalt et al., 2018).

Second, for the learning perspective of MPCK of mathematical modeling, PSTs in Germany demonstrated stronger competencies in evaluating students' answers than PSTs from Hong Kong and Mainland China but not in providing feedback on students' answers. As mentioned earlier, German participants' relatively rich experience in mathematical modeling from when they were in schools may have helped them to acquire stronger competencies in evaluating students' modeling work. As modeling work in German schools is often conducted in groups, German participants may have had some experience in evaluating other classmates' work but not in providing feedback. By contrast, in Mainland China, although optional mathematics modeling courses are available during the pre-service training period, owing to the direct teaching tradition and large class sizes, university lecturers will seldom require PSTs to solve mathematical modeling problems in small groups. However, existing studies suggest that PSTs' experiences of working in small groups to carry out mathematical modeling will provide them with thought-provoking opportunities to evaluate their own and their classmates' mathematical modeling work (English, 2003). Therefore, the Chinese mathematics teaching tradition and dominant direct teaching culture further contribute to explaining their weak competences with respect to evaluating students' work.

For the two aspects related to the teaching perspective- explaining the appropriateness of the task for teaching and suggesting appropriate teaching approaches - only a small proportion of participants in the three regions demonstrated high levels of professional competencies, which suggests that many PSTs experienced difficulties in both aspects. Such findings are consistent with those of earlier studies, which note that PSTs were unable to identify the potential of modeling tasks or experienced difficulties in identifying mathematical content related to the tasks (Kuntze, 2011; Paolucci \& Wessels, 2017). In addition, the Bonferroniadjusted post hoc test results suggest a common tendency among the three regions where significantly more PSTs from Hong Kong and Mainland China only attained low competency levels with respect to the teaching aspect, particularly in suggesting appropriate teaching approaches. Moreover, the post hoc test results do not reveal many differences between Hong Kong and Mainland China with respect to these two aspects.

Such differences may again first be attributed to the dominant cultural differences and traditional methods of mathematics teaching between the three regions. In Eastern Asian areas, teacher-centered approaches to teaching or direct teaching are the most popular mathematics 
teaching methods (Leung, 2001). However, student-centered approaches to teaching are required to teach mathematical modeling effectively (Ng, 2011; Tan \& Ang, 2016). Therefore, such approaches may present significant challenges for PSTs in Hong Kong and Mainland China owing to the lack of such experience in schools. Additionally, the differences in modeling experience in schools and the lack of training related to pedagogical strategies during the PST training period may help to explain this difference further.

\subsection{Discussion of the relationship between MCK and MPCK of mathematical modeling}

The study also explored the potential relationship between MCK and MPCK of mathematical modeling. The findings reported above suggested several patterns for the relationship between MCK and MPCK of mathematical modeling. First, it was found that those PSTs with strong foundations in MCK of mathematical modeling do not necessarily demonstrate similarly strong foundations in MPCK of mathematical modeling. Such a pattern may suggest that although it is widely accepted in mathematics teacher education research that MCK supports the development of MPCK (Tatto et al., 2020), the relationship between MCK and MPCK of mathematical modeling is complicated. It appears that the development of MCK of mathematical modeling alone will not necessarily facilitate the development of MPCK of mathematical modeling. Of course, this does not mean that MCK of mathematical modeling is unnecessary for the development of MPCK of mathematical modeling. The second pattern reported above clearly shows that PSTs - particularly those in Hong Kong and Mainland China - with weak foundations in MCK of mathematical modeling tend to experience difficulties in the four aspects of MPCK of mathematical modeling.

Overall, these findings may further imply that the MCK and MPCK of mathematical modeling are not developed evenly or at the same pace. Similar findings were also identified in earlier case studies (e.g., Doerr \& English, 2006; Kaiser et al., 2010). As reviewed above, in these earlier case studies, after the same intervention or after attending the same workshops, some participating PSTs or teachers mainly developed MCK of mathematical modeling, while the other participants mainly developed new MPCK-related aspects.

Additionally, regarding the relationship between MCK and MPCK of mathematical modeling, small cross-cultural differences were also identified. As reported above, the third pattern shows that some PSTs with poor foundations in MCK of mathematical modeling demonstrated high MPCK levels. However, as Table 7 illustrates, few PSTs from Hong Kong - compared to Germany and Mainland China - showing low MCK levels of mathematical modeling, demonstrate high MPCK levels. In addition, in the three regions, more PSTs with high MCK levels from Germany demonstrate correspondingly high MPCK mathematical modeling levels. Such differences may largely be attributed to the differences in mathematical modeling learning experienced in school (for Germany) and in university (for Germany and Mainland China).

\section{Conclusion, implications, and limitations}

Based on the findings reported above, we observed that PSTs from Germany exhibited the highest professional mathematical modeling competencies, while those from Hong Kong demonstrated the weakest professional competencies, with PSTs from Mainland China falling in between. Specifically, Bonferroni-adjusted post hoc tests suggest that for high professional competence levels, significant differences were mainly identified between Germany and Hong 
Kong. For low professional competence levels, significant differences were observed between Hong Kong and Germany and between Mainland China and Germany, indicating that significantly more PSTs from Hong Kong and Mainland China displayed low or very low levels of MCK and MPCK of mathematical modeling. By contrast, more participants from Germany were found to possess high or very high levels of MCK and MPCK of mathematical modeling. The study further found that MCK and MPCK of mathematical modeling were not evenly developed.

The present study is one of the few cross-cultural comparative studies hitherto on the topic of mathematical modeling competencies. Theoretically, the findings identified in the study not only contribute to the understanding of the strengths and weaknesses of PSTs' professional mathematical modeling competencies and the possible relationship between the two core cognitive competence facets-MCK and MPCK. The results further provide a more profound understanding of how specific curricular and educational traditions influence PSTs' professional mathematical modeling competencies.

In practical terms, the study's findings further contribute to the design of teacher professional development programs. First, the study found that few participants in each of the three regions demonstrated high professional mathematical modeling competency levels. Such findings therefore highlight the necessity of improving PSTs' professional competences in mathematical modeling at the international level. In cultural contexts with short histories of the inclusion of mathematical modeling, such as Mainland China and Hong Kong, it is particularly important to design courses purposely to improve the overall level of MCK and MPCK of mathematical modeling of PSTs, with particular attention paid to aspects such as how to provide feedback on students' answers and how to select suitable teaching methods.

Second, the uneven development relationship between MCK and MPCK of mathematical modeling suggests that, in practice, the development of a sole component of PSTs' professional mathematical modeling competencies is insufficient. Therefore, for regions like Mainland China, whose mathematics teacher preparation has long emphasized mathematics over mathematics pedagogy, it is necessary to make mathematics pedagogy for mathematical modeling teaching available beyond elective courses focusing on mathematical modeling at the university level only. Correspondingly, for those regions that have traditionally emphasized pedagogy or mathematics pedagogy, it is also necessary to enhance PSTs' MCK foundations during the pre-service training period.

The study has several limitations that should be mentioned. First, concerning the data collection methods, one considerable limitation is that we only used one modeling problem to investigate PSTs' professional competencies. Therefore, PSTs' professional mathematical modeling competencies may not have been as fully examined as possible. Future studies should consider including more items, particularly items of varying modeling complexity. Second, the number of participants from the three regions was insufficient for more advanced quantitative data analysis, limiting the results' generalizability, particularly regarding the relationship between MCK and MPCK of mathematical modeling.

Third, the number of institutions involved was relatively low, and we did not investigate the opportunities to learn mathematical modeling available during the pre-service training period, which may limit the possibility of establishing possible linkages between the specific characteristics of the institutions with PSTs' professional mathematical modeling competences. Moreover, few factors related to cultural tradition and educational contexts were discussed in the present study. Although it may be difficult, future studies should involve more participants from more institutions and should explore and compare the relationship cross- 
culturally between more countries to facilitate the identification of clear patterns concerning the influence of school and university curricular issues on PSTs' modeling competencies.

Supplementary Information The online version contains supplementary material available at https://doi.org/ 10.1007/s10649-021-10064-x.

Acknowledgements The authors would like to express their sincere gratitude to Gabriele Kaiser for her invaluable support, suggestions and ideas, which were a persistent inspiration and substantially helped to improve the paper.

Funding Open Access funding enabled and organized by Projekt DEAL.

Open Access This article is licensed under a Creative Commons Attribution 4.0 International License, which permits use, sharing, adaptation, distribution and reproduction in any medium or format, as long as you give appropriate credit to the original author(s) and the source, provide a link to the Creative Commons licence, and indicate if changes were made. The images or other third party material in this article are included in the article's Creative Commons licence, unless indicated otherwise in a credit line to the material. If material is not included in the article's Creative Commons licence and your intended use is not permitted by statutory regulation or exceeds the permitted use, you will need to obtain permission directly from the copyright holder. To view a copy of this licence, visit http://creativecommons.org/licenses/by/4.0/.

\section{References}

Anhalt, C. O., \& Cortez, R. (2016). Developing understanding of mathematical modeling in secondary teacher preparation. Journal of Mathematics Teacher Education, 19(6), 523-545.

Anhalt, C. O., Cortez, R., \& Bennett, A. B. (2018). The emergence of mathematical modeling competencies: An investigation of prospective secondary mathematics teachers. Mathematical Thinking and Learning, 20(3), 202-221.

Barquero, B., Bosch, M., \& Romo, A. (2018). Mathematical modelling in teacher education: Dealing with institutional constraints. ZDM-Mathematics Education, 50(1), 31-43.

Blömeke, S., \& Delaney, S. (2012). Assessment of teacher knowledge across countries: A review of the state of research. ZDM-Mathematics Education, 44(3), 223-247.

Blömeke, S, Kaiser, G., Döhrmann, M. \& Lehmann, R. (2010a). Mathematisches und mathematikdidaktisches Wissen angehender Sekundarstufen-I-Lehrkräfte im internationalen Vergleich [Mathematical and mathematical-didactical knowledge of future teachers for lower secondary level by international comparison]. In S. Blömeke, G. Kaiser, \& R. Lehmann (Eds.), TEDS-M 2008-Professionelle Kompetenz und Lerngelegenheiten angehender Mathematiklehrkräfte für die Sekundarstufe I im internationalen Vergleich [TEDS-M 2008 - Professional competence and opportunities to learn of future mathematics teachers for lower secondary level by international comparison] (pp. 197-238). Waxmann.

Blömeke, S., Kaiser, G., \& Lehmann, R. (Eds.). (2010b). TEDS-M 2008 - Professionelle Kompetenz und Lerngelegenheiten angehender Mathematiklehrkräfte für die Sekundarstufe I im internationalen Vergleich [TEDS-M 2008 - professional competence and opportunities to learn of future mathematics teachers for lower secondary level by international comparison]. Waxmann.

Blömeke, S., Seeber, S., Lehmann, R., Kaiser, G., Schwarz, B., Felbrich, A., \& Müller, C. (2008). Messung des fachbezogenen Wissens angehender Mathematiklehrkräfte [Measurement of the content-related knowledge of future mathematics teachers] In S. Blömeke, G. Kaiser, \& R. Lehmann (Eds.), Professionelle Kompetenz angehender Lehrerinnen und Lehrer - Wissen, Überzeugungen und Lerngelegenheiten deutscher Mathematikstudierender und - referendare - Erste Ergebnisse zur Wirksamkeit der Lehrerausbildung [Professional competence of future teachers - Knowledge, beliefs and opportunities to learn of German mathematics students and trainee mathematics teachers - First results concerning the efficacy of teacher education] (pp. 49-88). Waxmann. 
Blum, W. (2015). Quality teaching of mathematical modelling: What do we know, what can we do? In S. J. Cho (Ed.), Proceedings of the 12th international congress on mathematical education (pp. 73-96). Springer.

Blum, W., \& Leiß, D. (2007). How do students and teachers deal with modelling problems? In C. Haines, P. L. Galbraith, W. Blum, \& S. Khan (Eds.), Mathematical Modelling (ICTMA12): Education, Engineering and Economics (pp. 222-231). Horwood Academic.

Blum, W., \& Niss, M. (1991). Applied mathematical problem solving, modelling, applications, and links to other subjects-state, trends and issues in mathematics instruction. Educational Studies in Mathematics, 22(1), 37-68.

Borromeo Ferri, R., \& Blum, W. (2010). Mathematical modelling in teacher education - experiences from a modelling seminar. In V. Durand-Guerrier, S. Soury-Lavergne, \& F. Arzarello (Eds.), CERME-6 Proceedings of the Sixth Congress of the European Society for Research in Mathematics Education (pp. 2046-2055). INRP.

Brunner, M., Kunter, M., Krauss, S., Baumert, J., Blum, W., Dubberke, T., Jordan, A., Klusmann, U., Tsai, Y. M., \& Neubrand, M. (2006). Welche Zusammenhänge bestehen zwischen dem fachspezifischen Professionswissen von Mathematiklehrkräften und ihrer Ausbildung sowie beruflichen Fortbildung? [How is the content specific professional knowledge of mathematics teachers related to their teacher education and in-service training?]. Zeitschrift für Erziehungswissenschaft, 9(4), 521-544.

Bryan, C., Wang, T., Perry, B., Wong, N.-Y., \& Cai, J. (2007). Comparison and contrast: Similarities and differences of teachers' views of effective mathematics teaching and learning from four regions. ZDMMathematics Education, 39(4), 329-340.

Cetinkaya, B., Kertil, M., Erbas, A. K., Korkmaz, H., Alacaci, C., \& Cakiroglu, E. (2016). Pre-service teachers' developing conceptions about the nature and pedagogy of mathematical modeling in the context of a mathematical modeling course. Mathematical Thinking and Learning, 18(4), 287-314.

Chang, Y., Krawitz, J., Schukajlow, S., \& Yang, K. (2020). Comparing German and Taiwanese secondary school students' knowledge in solving mathematical modelling tasks requiring their assumptions. ZDMMathematics Education, 52(1), 59-72.

Charalambous, C. Y., Hill, H. C., Chin, M. J., \& McGinn, D. (2020). Mathematical content knowledge and knowledge for teaching: Exploring their distinguishability and contribution to student learning. Journal of Mathematics Teacher Education, 23, 579-613.

Didis, M. G., Erbas, A. K., Cetinkaya, B., Cakiroglu, E., \& Alacaci, C. (2016). Exploring prospective secondary mathematics teachers' interpretation of student thinking through analyzing students' work in modelling. Mathematics Education Research Journal, 28, 349-378.

Döhrmann, M, Kaiser, G., \& Blömeke, S. (2010). Messung des mathematischen und mathematikdidaktischen Wissens: Theoretischer Rahmen und Teststruktur [Measurement of the mathematical and mathematicaldidactical knowledge: Theoretical framework and test-structure]. In S. Blömeke, G. Kaiser, \& R. Lehmann (Eds.), TEDS-M 2008 - Professionelle Kompetenz und Lerngelegenheiten angehender Mathematiklehrkräfte für die Sekundarstufe I im internationalen Vergleich [TEDS-M 2008 - professional competence and opportunities to learn of future mathematics teachers for lower secondary level by international comparison] (pp. 169-196). Waxmann.

Doerr, H. D. (2007). What knowledge do teachers need for teaching mathematics through applications and modelling? In W. Blum, P. L. Galbraith, H. Henn, \& M. Niss (Eds.), Modelling and applications in mathematics education: The 14th ICMI study (pp. 69-78). Springer.

Doerr, H. M., \& English, L. D. (2006). Middle grade teachers' learning through students' engagement with modeling tasks. Journal of Mathematics Teacher Education, 9(1), 5-32.

English, L. D. (2003). Reconciling theory, research, and practice: A models and modelling perspective. Educational Studies in Mathematics, 54(2\&3), 225-248.

Galbraith, P., \& Stillman, G. (2006). A framework for identifying student blockages during transitions in the modelling process. Zentralblatt für Didaktik der Mathematik, 38(2), 143-162.

Greefrath, G., \& Vorhölter, K. (2016). Teaching and learning mathematical modelling. Approaches and Developments from German-speaking countries. Springer International Publishing.

Hankeln, C. (2020). Mathematical modeling in Germany and France: A comparison of students' modeling processes. Educational Studies in Mathematics, 103(2), 209-229.

Kaiser, G. (1995). Results from a comparative empirical study in England and Germany on the learning of mathematics in context. In C. Sloyer, W. Blum, \& I. D. Huntley (Eds.), Advances and Perspectives in the Teaching of Mathematical Modelling and Applications (pp. 83-95). Water Street Mathematics.

Kaiser, G. (2017). The teaching and learning of mathematical modeling. In J. Cai (Ed.), Compendium for Research in Mathematics Education (pp. 267-291). National Council of Teachers of Mathematics.

Kaiser, G., \& Maßß, K. (2007). Modelling in lower secondary mathematics classroom-problems and opportunities. In W. Blum, P. L. Galbraith, H.-W. Henn, \& M. Niss (Eds.), Modelling and applications in mathematics education: The 14th ICMI study (pp. 99-108). Springer. 
Kaiser, G., Schwarz, B., \& Tiedemann, S. (2010). Future teachers' professional knowledge on modeling. In R. Lesh, P. L. Galbraith, C. R. Haines, \& A. Hurford (Eds.), Modeling students' mathematical modeling competencies, ICTMA 13 (pp. 433-444). Springer.

Kleickmann, T., Richter, D., Kunter, M., Elsner, J., Besser, M., Krauss, S., \& Baumert, J. (2015). Content knowledge and pedagogical content knowledge in Taiwanese and German mathematics teachers. Teaching and Teacher Education, 46, 115-126.

Klein, F. (1907). Vorträge über den mathematischen Unterricht an den höheren Schulen [Lectures on the mathematical education on the secondary schools]. Teubner.

Kong, Q. (2000). New tendencey of mathematics curriculum reform in Hong Kong (in Chinese). Curriculum, Textbooks, Teaching Methods, 11, 59-61.

Kuckartz, U. (2016). Qualitative Inhaltsanalyse. Methoden, Praxis, Computerunterstützung [Qualitative content analysis. methods, practice, support by computers]. Beltz Juventa.

Kuntze, S. (2011). In-service and prospective teachers' views about modelling tasks in the mathematics classroom - results of a quantitative empirical study. In G. Kaiser, W. Blum, R. Borromeo Ferri, \& G. Stillman (Eds.), Trends in teaching and learning of mathematical modelling (ICTMA14) (pp. 279-288). Springer.

Lerman, S. (2001). Cultural, discursive psychology: A sociocultural approach to studying the teaching and learning of mathematics. Educational Studies in Mathematics, 46(1-3), 87-113.

Leung, F. K. S. (2001). In search of an East Asian identity in mathematics education. Educational Studies in Mathematics, 47(1), 35-51.

Leung, F. K. S. (2017). Making sense of mathematics achievement in East Asia: Does culture really matter? In G. Kaiser (Ed.), Proceedings of the 13th Internatioal Congress on Mathematical Education (pp. 201-218). Springer.

Lloyd, G. M. (1999). Two teachers' conceptions of a reform-oriented curriculum: Implications for mathematics teacher development. Journal of Mathematics Teacher Education, 2, 227-252.

Maßß, K. (2004). Mathematisches Modellieren im Unterricht: Ergebnisse einer empirischen Studie [Mathematical modeling in class: Results of an empirical study]. Franzbecker.

Maaß, K., \& Gurlitt, J. (2011). LEMA-Professional development of teachers in relation to mathematical modelling. In G. Kaiser, W. Blum, R. Borromeo Ferri, \& G. Stillman (Eds.), Trends in teaching and learning of mathematical modelling (ICTMA14) (pp. 629-639). Springer.

Mayring, P. (2014). Qualitative content analysis: Theoretical foundation, basic procedures and software solution. URN http://nbn-resolving.de/urn:nbn:de:0168-ssoar-395173 [last access: August, 21st, 2020]

Ministry of Education, China. (2017). Curriculum standards for high school mathematics (2017 version). Peoples' Educational Press.

Ng, K. E. D. (2011). Mathematical knowledge application and student difficulties in a design-based interdisciplinary project. In G. Kaiser, W. Blum, R. Borromeo Ferri, \& G. Stillman (Eds.), Trends in teaching and learning of mathematical modelling (ICTMA14) (pp. 107-116). Springer.

Ng, K. E. D. (2013). Teacher readiness in mathematical modelling: Are there differences between pre-service and in-service teachers? In G. A. Stillman, G. Kaiser, W. Blum, \& J. P. Brown (Eds.), Teaching mathematical modelling: Connecting to research and practice (pp. 339-348). Springer.

Ng, K. E. D., Widjaja, W., Chan, C. M. E., \& Seto, C. (2015). Developing teaching competencies through videos for facilitation of mathematical modelling in Singapore primary schools. In S. F. Ng (Ed.), The contributions of video and audio technology towards professional development of mathematics teachers (pp. 15-38). Springer.

Ni, Y., Li, Q., Li, X., \& Zhang, Z.-H. (2011). Influence of curriculum reform: An analysis of student mathematics achievement in Mainland China. International Journal of Educational Research, 50(2), 100-116.

Niss, M. (2015). Mathematical competencies and PISA. In K. Stacey \& R. Turner (Eds.), Assessing mathematical literacy: The PISA experience (pp. 35-56). Springer.

Organization for Economic Co-operation and Development (OECD) (2003). The PISA 2003 assessment framework - mathematics, reading, science and problem solving knowledge and skills. OECD.

Paolucci, C., \& Wessels, H. (2017). An examination of preservice teachers' capacity to create mathematical modeling problems for children. Journal of Teacher Education, 68(3), 330-344.

Schwarz, B. (2013). Professionelle Kompetenz von Mathematiklehramtsstudierenden - Eine Analyse der strukturellen Zusammenhänge. [Professional competence of future mathematics teacher students - an analysis of the structural relations]. Springer Spektrum.

Shulman, L. S. (1986). Those who understand: A conception of teacher knowledge. American Educator, 10(1), $43-44$.

Tan, L. S., \& Ang, K. C. (2013). Pre-service secondary school teachers' knowledge in mathematical modellingA case study. In G. A. Stillman, G. Kaiser, W. Blum, \& J. P. Brown (Eds.), Teaching mathematical modelling: Connecting to research and practice (pp. 405-415). Springer. 
Tan, L. S., \& Ang, K. C. (2016). A school-based professional development programme for teachers of mathematical modelling in Singapore. Journal of Mathematics Teacher Education, 19(5), 399-432.

Tatto, M. T., Lerman, S., \& Novotná, J. (2009). Overview of teacher education systems across the world. In R. Even \& D. L. Ball (Eds.), The professional education and development of teachers of mathematics: The 15th ICMI Study (pp. 15-23). Springer.

Tatto, M. T., Rodriguez, M. C., Reckase, M. D., Smith, W. M., Bankov, K., \& Pippin, J. (2020). The first five years of teaching mathematics (FIRSTMATH): Concepts, methods and strategies for comparative international research. Springer.

Weinert, F. E. (2001). Concept of competence: A conceptual clarification. In D. S. Rychen \& L. H. Salganik (Eds.), Defining and selecting key competencies (pp. 45-66). Hogrefe.

Winter, M., \& Venkat, H. (2013). Pre-service teacher learning for mathematical modelling. In G. Stillman, G. Kaiser, W. Blum, \& J. Brown (Eds.), Teaching mathematical modelling: Connecting to research and practice. (pp. 491-500). Springer.

Publisher's note Springer Nature remains neutral with regard to jurisdictional claims in published maps and institutional affiliations. 